Editorial

\title{
Hajj and the public health significance of mass gatherings
}

Ziad A. Memish ${ }^{7}$

Mass gatherings (MG) refer to groups of people measured in the thousands, some definitions suggest 25000 and above $[1,2]$. MG present unique health challenges distinct from the average population cohort of the same size. Within the context of an exploding global population, widely accessible air travel and unprecedented frequency of $M G$, health issues relating to MG medicine are more commonly encountered. Safeguarding individual and mass health at such gatherings is termed public health security [3].

MG-related infection is an emerging subspecialty in global epidemiology and while an extensive body of information and experiences now exists, not all are published and accessible to MG planners and public health administrators,and vital information awaits dissemination [4]. Infectious diseases have long played a substantial part in shaping human history and continue to be an issue of pressing concern. In this era of the "flat world", globalization facilitates the spread of numerous infectious agents to all corners of the planet. No locale is too remote for a threatening pathogen, be West Nile Virus arriving in the United States or Rift Valley Fever reaching the Arabian Peninsula [5].

Public health risks focus on infectious agents both specific to humans (which are broadly and uniformly distributed) and zoonoses (infectious agents transmitted from animals to humans) which tend to be far more localized in their geographical distribution. Research has shown that emerging infectious diseases have roughly quadrupled over the past 50 years, and pathogens that originate in wild animals (wildlife zoonoses) account for the majority of such diseases. Further, the frequency of infectious disease emergence correlates highly with human population density, the density of mammalian species and human population growth. Some data exist indicating that emerging diseases (specifically zoonoses) are more likely to be seen in tandem with progressive global warming [6].

The role played by travel, migration, trade and human exchanges in the propagation of epidemic infectious disease is well known. Almost one billion people cross international borders each year. In 2008, there were 924 million international arrivals, 16 million more than 2007 [7]. Travel-related infection is reaching previously uncharted dimensions of scale and complexity and it is the Hajj experience that provides invaluable insights in predicting travelrelated health challenges.

Hajj is the largest and most longstanding annual MG event on earth. It is the site of some of the greatest crowd densities known to man. Following an exponential rise in the past decade, Hajj is now the most internationally, ethnically, demographically and clinically diverse assembly today. The numbers of non-Saudi pilgrims attending the Hajj routinely exceed 2 million people, travelling to Makkah from over 180 countries, pushing the Hajj congregation towards the 3 million mark. The sheer dimensions of Hajj demand extraordinary imagination and agility from planners.

Because of the wide global attendance, international partnerships and collaborations in this process are increasingly necessary, as countries sending pilgrims ensure their fitness for travel and, later, continue to monitor the impact of the returning pilgrims to their countries of origin. The scale and diversity of Hajj presents an enormous public health security challenge to Saudi Arabian authorities who, as functionaries to the Custodians of the two holy sites (Makkah Al Mukarramah and Medina Al Munnawarah) must provide extensive, multi-faceted programmes to serve the "Guests of God" [8].

Because of this remarkable scale, and its annual occurrence, preparations for the public health safety and security of this event are extraordinarily challenging, requiring an intensely collaborative approach. Multiple domestic agencies must work together to prepare for Hajj within a matter of months. While most MG of this scale have the greater part of a decade to prepare, Saudi Arabia readies itself for the massive influx within a mere 11-month lead time demanding precision in organization and the surge deployment of massive semi-permanent infrastructures and manpower.

Such efforts are accomplished through intense inter-Ministry collaboration. Saudi authorities, including 
the Ministry of Health $(\mathrm{MOH})$, the Ministry of Hajj, the Ministry of Interior (MOI), the Saudi Red Crescent and other government health sectors, including the Saudi Arabian National Guard Health Affairs, the Ministry of Defence and Aviation (MODA) and the Security forces, come together with a common focus of public health security. Collectively these agencies have accumulated decades of experience managing Hajj from every aspect, whether it be management and repatriation of the sick at Hajj, anticipating crowd turbulence or handling the arrival of over a million and a half head of cattle for ritual sacrifice.

With over 1.3 billion Muslims globally, many more seek to make Hajj than can be safely accommodated. In a delicate choreography of diplomacy and service, Saudi Arabia must balance the dual roles of both Custodian to the Holy Sites and Guardians to the Guests of God. Representatives of the Saudi authorities must safeguard Hajj for millions annually while at the same time carefully controlling its access to maintain public health safety and security.

Note must be made of the important work facilitated by the Saudi immigration authorities which safeguards public health, possibly one of the largest public health interventions today. Saudi Arabia provides visas to every eligible pilgrim, setting an annual quota of 1000 visas per million populations for every country. Access to all holy sites is strictly limited to visa and permit holders. The visa application process facilitates enforcement of basic public health requirements by specifying visa eligibility based on evidence of mandatory immunization (including against polio and yellow fever for pilgrims arriving from countries with active disease and meningococcal disease for all pilgrims, all important causes of disease at Hajj). Immigration thus becomes a tool facilitating public health security for such a massive gathering [9].

Given the complex, multi-factorial elements that comprise the preparation for Hajj, Hajj medicine clearly falls within the realm of public health security and must be recognized as such. Further, because of the Kingdom's ability to effectively surge public health resources at short notice, it is in a position to make a unique contribution to other gatherings facing bioterrorism or disaster preparedness demands through exchange of information and experiences. Surge capacity is integral to public health security in which the Kingdom has exceptional experience. It is for those reasons that Saudi Arabia was recognized and acknowledged to be a World Health Organization Collaborating Centre for MG Medicine in September 2012 tasked with training, research and providing guidance and advice to MG administrators across the globe.

\section{References}

1. Arbon P, Bridgewater FHG, Smith C. Mass gathering medicine: a predictive model for patient presentation and transport rates. Prehospital and Disaster Medicine, 2001, 16:150-158.

2. Mitchell JA, Barbera MD. Mass gathering medical care: a twenty-five year review. Prehospital and Disaster Medicine, 1997, 12:72-79.

3. Ahmed QA, Barbeschi M, Memish ZA. The quest for public health security at Hajj: the WHO guidelines on communicable disease alert and response during mass gatherings. Travel Medicine and Infectious Disease, 2009, 7:226-230.

4. Memish ZA et al.Emergence of medicine for mass gatherings: lessons from the Hajj. Lancet Infectious Diseases, 2012, 12:56-65.

5. Balkhy HH, Memish ZA. Rift Valley fever: an uninvited zoonosis in the Arabian peninsula [Review]. International Journal of Antimicrobial Agents, 2003, 21:153-157.
6. Blancou J et al. Emerging or re-emerging bacterial zoonoses: factors of emergence, surveillance and control. Veterinary Research, 2005, 36(3):507-522.

7. United Nations World Tourism Organization. UNWTO world tourism barometer (2009) (http://unwtp.orh/facts/eng/pdf/ barometer/UNWTP_barom09_1_en_excrept.pdf, accessed 1 October 2013).

8. Ahmed QA, Memish ZA. Hajj medicine for the Guests of God: a public health frontier revisited. Journal of Infection and Public Health, 2008, 1:57-61.

9. Memish ZA, Al-Rabeeah AA. Health conditions of travellers to Saudi Arabia for the pilgrimage to Mecca (Hajj and Umra) for 1434 (2013). Journal of Epidemiology and Global Health, 2013, 3:59-61. 